\title{
The Effects of an Adolescent Asthma Education Intervention on Knowledge, Intention, Behavior, Self-Efficacy and Self-Consciousness
}

\author{
Kara Zografos ${ }^{1}$, Helen Hopp Marshak ${ }^{2}$, David T. Dyjack ${ }^{2}$ and Christine Neish ${ }^{2}$ \\ ${ }^{1}$ California State University, Fresno \\ ${ }^{2}$ Loma Linda University
}

\begin{abstract}
In this study, we evaluated the effects of an asthma education intervention, guided by social cognitive theory, on knowledge, intention, behavior, self-efficacy, and self-consciousness. The sample consisted of 87 asthmatic adolescents in six middle and/or high schools in California. A non-equivalent comparison group design, with delayed intervention in the comparison group, was utilized. We implemented a modified version of the American Lung Association's Kickin Asthma curriculum. Self-report questionnaires assessing the key study variables were administered at baseline, at immediate postintervention, and five weeks after the intervention. There were no statistically significant differences at post-test, controlling for pre-test values, for any of the study variables between the intervention $(\mathrm{n}=51)$ and comparison groups $(\mathrm{n}=35)$. After collapsing across groups, however, there were statistically significant improvements following the intervention for knowledge, intention, selected behavior variables, and self-efficacy. The evaluation of this theory-based asthma education intervention demonstrates the positive impact this curriculum can have on a sample of asthmatic adolescents.
\end{abstract}

(C) 2010 Californian Journal of Health Promotion. All rights reserved.

Keywords: asthma, adolescents, asthma education curriculum, social cognitive theory.

\section{Introduction}

Asthma is a chronic disorder of the airways that involves a complex interaction of airflow obstruction, bronchial hyper responsiveness, and underlying inflammation (National Heart, Lung, and Blood Institute [NHLBI], 2007). Typically, asthma is divided into two types: allergic (extrinsic) and non-allergic (intrinsic). Allergic asthma is more common and is characterized by symptoms that are triggered by an allergic reaction to allergens such dust mites, pet dander, pollen, mold, etc., while the etiology of nonallergic asthma is often unknown, but can be triggered by factors not related to allergies (anxiety, stress, exercise, cold air, etc.). The symptoms of both types of asthma, however, are similar and include coughing, wheezing, shortness of breath, rapid breathing, and chest tightness (Asthma and Allergy Foundation of America, [AAFA], 2005). Although asthma cannot be cured, it can be prevented and controlled through the avoidance of triggers and the appropriate use of medications. Asthma medications are divided into two types: quickrelief and long-term control. Quick-relief medications (bronchodilators) quickly open swollen airways, while long-term control medications reduce airway inflammation and lessen the frequency and severity of episodes over time (MayoClinic, 1998-2010).

From 2006 to 2008, approximately $7.8 \%$ of the United States population reported that they currently had asthma. Reported asthma rates, however, were highest among children and adolescents. In 2008, more than 10 million children ages 0-17 in the United States reported that they had received a diagnosis of asthma, with more than 4 million experiencing an asthma attack or episode within the past 12 months (Centers for Disease Control [CDC], 2008). In California, approximately 475,000 children and adults reported at least one emergency room or urgent care visit due to asthma. California children also missed 1.9 million days of school 
because of asthma (California Health Interview Survey, [CHIS], 2005). The actual number of asthmatics, however, especially those $0-4$ years of age, is most likely much higher. According to the National Asthma Education and Prevention Program Expert Report 3 (2007), it is difficult to diagnose asthma among children 0-4 years of age due to the difficulty in obtaining objective measurements of lung function in this age group, i.e. infants and small children are not able to perform pulmonary function testing. Therefore, it is possible that asthma is under-diagnosed among those $0-4$ years of age.

Compared to younger children, adolescents have a higher prevalence of asthma, suffer more frequent exacerbations, and have more near-fatal episodes (Berg, Tichacek, \& Theodorakis, 2004; Bruzzese, Bonner, Vincent, et al., 2004). Morbidity rates among adolescents are also high, with many adolescents reporting that their symptoms contribute to avoidance of school and school-related activities (Environmental Protection Agency, 2001). Authors have also reported a poor understanding of asthma management, underdiagnosis, and poor compliance among this population (Gibson, Henry, Vimpani, \& Halliday, 1995; Price, 1996; Price \& Kemp, 1999; Buston \& Wood, 2000).

A number of asthma education interventions are designed to be implemented in the school setting (Lurie, 1998; Thies, \& McAllister, 2001; Valeros, Kieckhefer, \& Patterson, 2001). Previous studies show school-based asthma education interventions to be cost-effective. Compared to other settings, attendance rates also tend to be higher in these settings (Christiansen $\&$ Zuraw, 2002). The effectiveness of these interventions have also been documented in recent studies. Magzamen, Patel, Davis, Edelstein, and Tager (2008) implemented the American Lung Association's (ALA) Kickin' Asthma curriculum to middle and high school students and found fewer activity limitations, sleep disturbances, and emergency department visits or hospitalizations among those who participated in the intervention. Implementation of a classroom-based asthma education curriculum resulted in an increase in asthma knowledge and self-efficacy. Although not statistically significant, increases in quality of life were also reported among those who participated in this intervention (Shaw, Marshak, Dyjack, \& Neish, 2005).

Our research utilized several constructs of Bandura's social cognitive theory (SCT) to examine the effects of this intervention on various asthma-related outcome variables. SCT was selected based on its success in the development of other asthma education interventions (Mesters, Meertens, Crebolder, \& Parcel, 1993; McGhan et al., 2003; Shaw et al., 2005). Similar to these interventions, constructs such as vicarious and mastery experiences were incorporated into the existing ALA Kickin Asthma education education curriculum used in our study to enhance feelings of self-efficacy for performing asthma control behaviors. This adapted curriculum was used as the basis for this intervention because it can be easily incorporated into the school setting and it addresses some of the unique needs of this population (American Lung Association, 2010).

The purpose of this study was to evaluate the effects of this school-based asthma education intervention on adolescents' knowledge, selfefficacy, and self-consciousness. Other variables assessed were self-reported asthma management behaviors (utilization of the peak flow meter, holding chamber, and inhaler, trigger avoidance, and medication adherence) and intentions related to those behaviors when alone and when in the presence of peers.

\section{Methods}

\section{Study Design}

We used a non-equivalent comparison group design, with delayed intervention as the comparison condition (three week delay), to assess intervention outcomes. This study consisted of six schools divided into three cohorts, with each cohort consisting of two schools (an intervention school and a comparison school). For each cohort, the intervention school received the intervention immediately, while the comparison school received the intervention three weeks later. Baseline measurements of knowledge, intention, behavior, self-efficacy, and self-consciousness 
were collected for participants in both the intervention and comparison groups at Week 1. Measurements were collected again at Week 3. Due to the long length of the questionnaire, those from the comparison schools did not take the knowledge assessment again at Week 3; therefore, only the immediate effect of the intervention on intention, behavior, self-efficacy, and self-consciousness between study groups could be determined at Week 3. Follow-up measurements on all study variables were also collected 5 weeks after the intervention (see Figure 1).

Figure 1

Diagram of Non-Equivalent Comparison Group Design with Delayed Intervention in One Group

\begin{tabular}{|c|c|c|c|c|c|c|c|c|c|c|c|}
\hline & & 1 & 2 & 3 & 4 & 5 & 6 & 7 & 8 & 9 & 10 \\
\hline Schools $1,3 \& 5$ (I) & NR & $\mathrm{O} / \mathrm{X}$ & $\mathrm{X}$ & $\mathrm{X} / \mathrm{O}$ & & & & & $\mathrm{O}$ & & \\
\hline Schools $2,4 \& 6(C)$ & NR & $\mathrm{O}$ & & $\mathrm{O} / \mathrm{X}$ & $\mathrm{X}$ & $\mathrm{X} / \mathrm{O}$ & & & & & $\mathrm{O}$ \\
\hline
\end{tabular}

\section{Sample}

Six schools (one public middle school in the Fresno Unified School District, four public middle schools in the Clovis Unified School District, and one private K-12 school in Fresno County) were selected to participate in this study. The schools selected were those in which the first author had established rapport with administrative staff and/or school nurses. School nurses identified asthmatic adolescents based on records of asthma medication use in their medical records. Parental consent forms were mailed and/or given to students to give to their parents. A total of 104 adolescents participated in this study; however, some of the participants did not attend all of the sessions. Of the 104 adolescents who gave assent, 87 (83.6\%) participated in the entire study. Institutional Review Board approval was granted prior to study implementation.

\section{Intervention}

The asthma education curriculum, entitled Kickin' Asthma, was developed by the American Lung Association. The curriculum consists of four, 45-minute sessions. For the purpose of this study, the curriculum was adapted and consisted of six, 40-minute sessions held twice a week over a three week period. This modification was made to accommodate the needs of the schools (i.e. to conduct the sessions within a 40-minute lunch period) and to allow for the integration of various social cognitive theory constructs. The first author taught each of the sessions.

Several SCT constructs, including self-efficacy, observational learning, reinforcement, and outcome expectations, were incorporated into the intervention. Session \#1 involved the administration of the pre-test. Session \#2 provided opportunities for the participants to get to know each other which also included information about the definition and pathophysiology of asthma. Session \#3 involved a discussion pertaining to warning signs and triggers for asthma episodes. During this session, students identified their personal triggers and learned how to reduce or eliminate them from their environments. Session \#4 included a discussion about asthma medications and devices, including the peak flow meter, holding chamber, and inhaler. Each participant was given a peak flow meter and holding chamber to use during this session and to take home for future use. Vicarious and mastery experiences, two key ways to enhance selfefficacy, were also incorporated into this 
session. Participants engaged in observational learning as the researcher demonstrated the proper way to use each device. Self-efficacy was targeted through mastery experiences as participants performed a series of tasks associated with each of the devices. Small gifts, i.e. small notebooks, pencils, erasers, etc., were distributed as reinforcement for correctly demonstrating the behaviors. During session \#5, social outcome expectations, specifically how asthmatic adolescents expect their peers to react when they utilize their peak flow meters, holding chambers, and inhalers were addressed. Participants engaged in role playing activities designed to decrease feelings of selfconsciousness about performing asthma management behaviors in the presence of peers. Session \#6 involved the administration of the post-test. The curriculum guide is available from the first author upon request.

\section{Measures}

We developed a self-administered 88-item asthma questionnaire, using items and scales from validated questionnaires as well as newly developed items, to measure the five outcome variables: (1) knowledge about asthma, (2) intention to perform asthma management behaviors, (3) actual asthma management behaviors, (4) self-efficacy for performing asthma management behaviors, and (5) selfconsciousness regarding the asthmatic condition. All validated questionnaires were also tested for reliability.

Participants completed a 31-item asthma knowledge questionnaire developed by Fitzclarence and Henry to assess asthma knowledge. The authors of this questionnaire reported a reliability coefficient of 0.94 . Correlations with parent knowledge confirmed face validity, content validity, and concurrent validity (Fitzclarence \& Henry, 1990). This asthma questionnaire was also validated in a peer-led asthma education intervention among adolescents (Gibson, Shah, \& Mamoon, 1998). The questionnaire includes six items requiring short answer responses and 25 items with response options of "true," "false," or "unsure." Scores were expressed as a percent of correct responses. Eight items using a six-point Likert- type scale ( $1=$ strongly disagree; $6=$ strongly agree) assessed intention. This subset produced a reliability coefficient of 0.83 . Five items assessed intention to perform asthma management behaviors when alone (e.g. I intend to avoid one or more of my asthma triggers when I am at home; I intend to take my bronchodilator at the first sign of an asthma episode; I intend to take my anti-inflammatory asthma medication each day as prescribed by my doctor to prevent my asthma episodes from occurring; I intend to use my peak flow meter twice per day to measure air flow in my lungs; and I intend to use my holding chamber each time I take my asthma medicine), while three items assessed intention to perform asthma management behaviors in the presence of peers (e.g. I intend to avoid one or more of my asthma triggers when I am with my friends; I intend to take my bronchodilator at the first sign of an asthma episode when I am with my friends; and I intend to use my holding chamber each time I take my asthma medication when I am with my friends). A mean score for each domain (alone and in the presence of peers) was calculated.

Asthma-related behavior frequency was assessed with a newly developed seven-item categorical scale. Two items assessed current peak flow meter and holding chamber utilization, while five items assessed self-reported asthma management behavior frequency in the past week. These behaviors included utilization of the peak flow meter, holding chamber, and/or inhaler, trigger avoidance, and medication adherence. For the items assessing current peak flow meter and holding chamber utilization, the response options included "often", "sometimes", and "never." For the items assessing selfreported asthma management behavior frequency in the past week, the response options ranged from "I did not use/do the intended behavior" to the number of days the behavior occurred (ranging from one to four or more times or from one to six or more days depending on the question). In this study, each behavior item was evaluated separately. These items were assessed for internal consistency (Cronbach's alpha: $r=0.216$ ). For self-efficacy, we used the 14-item Child Asthma Self-Efficacy Questionnaire with a five-point Likert-type scale 
$(1=$ not at all sure; $6=$ completely sure $)$. Reliability coefficients of 0.75 for the asthma attack prevention domain (eight items), and 0.82 for the asthma attack management domain (six items) have been established. The questionnaire also demonstrated construct validity (Bursch, Schwankovsky, Gilbert, and Zieger, 1999). Mean scores were calculated across the 14 items to provide an overall self-efficacy score.

Three questions were developed using a sixpoint Likert-type scale ( $1=$ strongly disagree; $6=$ strongly agree) to assess self-consciousness about performing asthma management behaviors in the presence of peers. They were assessed for internal consistency and achieved a reliability coefficient of 0.80 . These items assessed social outcome expectations, such as how participants felt their peers would react when they used asthma management devices (peak flow meters, holding chambers, and inhalers), in their presence. Mean scores were calculated across the three items for an overall self-consciousness score.

\section{Data Collection}

The asthma education intervention was implemented from October 2005 to May 2006. The six schools were staggered over this time period into three cohorts, with each cohort consisting of two schools (an intervention school and a comparison school). During the first week, questionnaires were administered to both schools (intervention and comparison). The researcher explained to the participants in the comparison school why measurements were going to be taken during the first week and again during the third week (to compare the effectiveness of the asthma education intervention), and assured the comparison group that they would also receive the same intervention during the third week. During the first week, the intervention school received Session \#1. During the second and third weeks, the intervention school continued to receive the asthma curriculum, while the other school served as the comparison group. During the third week, questionnaires were administered to both schools in each cohort to assess the immediate effects of the intervention on four of the study variables: (1) intention, (2) behavior,
(3) self-efficacy, and (4) self-consciousness. The comparison school also began Session \#1 of the intervention during the third week. During the fourth and fifth weeks, the comparison school continued to receive the asthma curriculum. Also during the fifth week, a questionnaire was administered to the comparison school. Followup questionnaires were administered to the intervention school during the eighth week and to the comparison school during the tenth week.

\section{Statistical Tests}

We performed statistical analyses using the Statistical Package for the Social Sciences (version 12.0) software. The General Linear Model was used to determine if there were differences between the two groups (intervention vs. comparison) for continuous level variables (i.e., intentions; self-efficacy; and selfconsciousness) after controlling for baseline values. The Mann-Whitney U statistic was used to determine if there were differences between the two study groups for ordinal behavior variables (i.e., number of days a peak flow meter was used in the past week; number of days a holding chamber was used in the past week; number of times triggers were avoided in the past week; number of times a bronchodilator was used to stop asthma in the past week; and number of times an anti-inflammatory was skipped in the past week). In addition, paired ttests were used to compare baseline values for continuous level variables with immediate postintervention and 5 week follow-up values after the comparison group received the delayed intervention by combining the two groups to determine if there were changes from baseline. The non-parametric equivalent of the paired-test, the Marginal Homogeneity test, was used to assess if there were differences from baseline to immediate post-intervention and five week follow-up for the ordinal behavior variables.

\section{Results}

\section{Demographic Data and Baseline Values}

Participants were predominately Caucasian (49.0\% in the intervention group; $47.1 \%$ in the comparison group) and male $(62.7 \%$ in the intervention group; $60.0 \%$ in the comparison group). The majority of the participants were in 
the 7 th grade $(62.7 \%$ in the intervention group; $42.9 \%$ in the comparison group) and 13 years of age. There were no differences in demographic variables between intervention and comparison groups at baseline (see Table 1). In addition, there were no differences in the five study variables between intervention and comparison groups at baseline (see Table 2).

Table 1

Baseline Differences in Demographic Variables Between Intervention and Comparison Groups

\begin{tabular}{|c|c|c|c|c|c|c|c|}
\hline \multirow[b]{2}{*}{ Variable } & \multicolumn{2}{|c|}{$\begin{array}{l}\text { Intervention } \\
\text { Group }\end{array}$} & \multicolumn{2}{|c|}{$\begin{array}{c}\text { Comparison } \\
\text { Group }\end{array}$} & \multicolumn{2}{|r|}{ Total } & \multirow[t]{2}{*}{ p-value } \\
\hline & $\mathbf{N}$ & $\begin{array}{r}\text { M (SD) } \\
\text { or \% }\end{array}$ & $\mathbf{N}$ & $\begin{array}{c}\text { M (SD) } \\
\text { or \% }\end{array}$ & $\mathbf{N}$ & $\begin{array}{c}\text { M (SD) } \\
\text { or \% }\end{array}$ & \\
\hline Age & 51 & $13.43(1.51)$ & 35 & $13.08(.70)$ & 86 & $13.29(1.25)$ & .159 \\
\hline $\begin{array}{l}\text { Gender } \\
(\% \text { male })\end{array}$ & 32 & $62.7 \%$ & 21 & $60.0 \%$ & 53 & $61.6 \%$ & .797 \\
\hline \multicolumn{7}{|l|}{ Grade Level } & \multirow{6}{*}{.164} \\
\hline $7^{\text {th }}$ & 32 & $62.7 \%$ & 15 & $42.9 \%$ & 47 & $54.7 \%$ & \\
\hline $8^{\text {th }}$ & 17 & $33.3 \%$ & 19 & $54.3 \%$ & 36 & $41.9 \%$ & \\
\hline $9^{\text {th }}$ & 1 & $2.0 \%$ & 0 & $0 \%$ & 1 & $1.2 \%$ & \\
\hline $10^{\text {th }}$ & 0 & $0 \%$ & 1 & $2.9 \%$ & 1 & $1.2 \%$ & \\
\hline $11^{\text {th }}$ & 1 & $2.0 \%$ & 0 & $0 \%$ & 1 & $1.2 \%$ & \\
\hline \multicolumn{7}{|l|}{ Ethnicity } & \multirow{7}{*}{.791} \\
\hline White & 24 & $49.0 \%$ & 16 & $47.1 \%$ & 40 & $48.2 \%$ & \\
\hline African American & 2 & $4.1 \%$ & 3 & $8.8 \%$ & 5 & $6.0 \%$ & \\
\hline Asian & 1 & $2.0 \%$ & 2 & $5.9 \%$ & 3 & $3.6 \%$ & \\
\hline Hispanic & 7 & $14.3 \%$ & 4 & $11.8 \%$ & 11 & $13.3 \%$ & \\
\hline Native American & 1 & $2.0 \%$ & 0 & $0 \%$ & 1 & $1.2 \%$ & \\
\hline Other & 14 & $28.6 \%$ & 9 & $26.5 \%$ & 23 & $27.7 \%$ & \\
\hline
\end{tabular}

\section{Comparisons Between Intervention and Comparison Groups at Immediate Post- Intervention}

The immediate effect of the intervention on intention, behavior, self-efficacy, and selfconsciousness between study groups was assessed. There were no statistically significant differences between intervention and comparison groups at week three for any of the variables studied after controlling for baseline values.

Overall Changes from Baseline to Immediate Post-Intervention and 5 Week Follow-Up Since both groups ultimately received the intervention (delayed intervention for the comparison group), comparisons from baseline to immediate post-intervention to five week follow-up were made after collapsing across study conditions.

\section{Knowledge}

There was a statistically significant improvement in asthma knowledge scores from baseline (mean $=7.64, \mathrm{SD}=7.18)$ to immediate postintervention $($ mean $=16.44, \mathrm{SD}=6.09), \mathrm{p}=$ $\leq .001$, but scores declined significantly from immediate post-intervention $($ mean $=16.44, \mathrm{SD}$ $=6.09$ ) to the five week follow-up (mean $=8.80$, $\mathrm{SD}=9.18), \mathrm{p}=\leq .001($ see Table 3$)$. 
Table 2

Baseline Differences in Study Variables Between Intervention and Comparison Groups

\begin{tabular}{|c|c|c|c|c|c|c|c|}
\hline \multirow[b]{2}{*}{ Dependent Variable } & \multicolumn{2}{|c|}{ Intervention } & \multicolumn{2}{|c|}{ Comparison } & \multicolumn{2}{|c|}{ Total } & \multirow[t]{2}{*}{ p value } \\
\hline & $\mathbf{N}$ & $\begin{array}{c}\text { Mean } \\
\text { (SD) }\end{array}$ & $\mathbf{N}$ & $\begin{array}{c}\text { Mean } \\
\text { (SD) }\end{array}$ & $\mathbf{N}$ & $\begin{array}{c}\text { Mean } \\
\text { (SD) }\end{array}$ & \\
\hline \multicolumn{8}{|l|}{ Intentions $^{\mathrm{a}}$} \\
\hline Alone & 50 & $\begin{array}{c}3.74 \\
(1.19)\end{array}$ & 35 & $\begin{array}{c}3.70 \\
(1.14)\end{array}$ & 85 & $\begin{array}{c}3.72 \\
(1.16)\end{array}$ & .858 \\
\hline Presence of Peers & 50 & $\begin{array}{c}3.63 \\
(1.18)\end{array}$ & 35 & $\begin{array}{c}3.78 \\
(1.15)\end{array}$ & 85 & $\begin{array}{c}3.69 \\
(1.16)\end{array}$ & .537 \\
\hline \multicolumn{8}{|l|}{ Behavior } \\
\hline Spacer use* & 49 & $\begin{array}{l}2.31 \\
(.77)\end{array}$ & 34 & $\begin{array}{l}2.18 \\
(.80)\end{array}$ & 83 & $\begin{array}{l}2.25 \\
(.78)\end{array}$ & .453 \\
\hline Peak flow meter use* & 48 & $\begin{array}{l}2.48 \\
(.69)\end{array}$ & 34 & $\begin{array}{l}2.59 \\
(.66)\end{array}$ & 82 & $\begin{array}{l}2.52 \\
(.67)\end{array}$ & .420 \\
\hline $\begin{array}{l}\text { \# of days a peak flow } \\
\text { meter used (past wk) }\end{array}$ & 49 & $\begin{array}{c}1.43 \\
(1.14)\end{array}$ & 34 & $\begin{array}{c}1.82 \\
(1.68)\end{array}$ & 83 & $\begin{array}{c}1.59 \\
(1.39)\end{array}$ & .237 \\
\hline $\begin{array}{l}\text { \# of days a spacer used } \\
\text { (past wk) }\end{array}$ & 47 & $\begin{array}{c}2.15 \\
(2.20)\end{array}$ & 34 & $\begin{array}{c}2.56 \\
(2.38)\end{array}$ & 81 & $\begin{array}{c}2.32 \\
(2.27)\end{array}$ & .426 \\
\hline $\begin{array}{l}\text { \# of times triggers avoided } \\
\text { (past wk)* }\end{array}$ & 47 & $\begin{array}{c}2.34 \\
(1.42)\end{array}$ & 33 & $\begin{array}{c}2.33 \\
(1.43)\end{array}$ & 80 & $\begin{array}{c}2.34 \\
(1.41)\end{array}$ & .992 \\
\hline $\begin{array}{l}\text { \# of times a bronchodilator } \\
\text { was used to stop asthma } \\
\text { (past wk)* }\end{array}$ & 49 & $\begin{array}{c}2.06 \\
(1.40)\end{array}$ & 33 & $\begin{array}{c}2.09 \\
(1.47)\end{array}$ & 82 & $\begin{array}{c}2.07 \\
(1.42)\end{array}$ & .844 \\
\hline $\begin{array}{l}\text { \# of times anti-inflammatory } \\
\text { skipped (past wk)* }\end{array}$ & 48 & $\begin{array}{c}2.02 \\
(1.38)\end{array}$ & 32 & $\begin{array}{l}2.00 \\
(1.16)\end{array}$ & 80 & $\begin{array}{c}2.01 \\
(1.29)\end{array}$ & .684 \\
\hline Self-Efficacy $^{b}$ & 50 & $\begin{array}{l}3.77 \\
(.68)\end{array}$ & 35 & $\begin{array}{l}3.81 \\
(.65)\end{array}$ & 85 & $\begin{array}{l}3.79 \\
(.66)\end{array}$ & .804 \\
\hline Self-Consciousness ${ }^{a}$ & 50 & $\begin{array}{l}2.30 \\
(1.4)\end{array}$ & 35 & $\begin{array}{l}2.06 \\
(1.5)\end{array}$ & 85 & $\begin{array}{l}2.20 \\
(1.4)\end{array}$ & .441 \\
\hline
\end{tabular}

${ }^{\mathrm{a}}$ Possible score range $=1-6$.

${ }^{\mathrm{b}}$ Possible score range $=1-5$.

*Non-parametric statistics were calculated for these variables because they were assessed using ordinal scales.

Means/SD are shown for ease of interpretation.

\section{Intention}

There were statistically significant improvements in the "when alone" mean intention scores from baseline (mean $=3.66, \mathrm{SD}$ $=1.19)$ to immediate post-intervention (mean $=$ 4.21, $\mathrm{SD}=1.22), \mathrm{p}=\leq .001$, and from baseline (mean $=3.66, \mathrm{SD}=1.19)$ to the 5 week followup (mean $=4.01, \mathrm{SD}=1.20), \mathrm{p}=.006$. There were no statistically significant improvements in the "presence of peers" intention score for any of the time points examined (see Table 3 ).

\section{Behavior}

There were statistically significant improvements in holding chamber use from baseline $($ mean $=2.23, \mathrm{SD}=.78)$ to immediate post-intervention $($ mean $=2.04, \mathrm{SD}=.84)$ and from baseline (mean $=2.23, \mathrm{SD}=.78)$ to the five week follow-up $($ mean $=1.93, \mathrm{SD}=.80)$. There were statistically significant improvements found at each time point examined for peak flow meter use and for number of days a peak flow meter was used in the past week. There was also a statistically significant improvement in the number of days a holding chamber was used in the past week from baseline (mean $=1.45, \mathrm{SD}=2.33$ ) to the five week follow-up $($ mean $=2.28, \mathrm{SD}=2.67), \mathrm{p}=$ .011. There were no statistically significant differences in the following four behaviors for any time point examined: number of times one or more asthma triggers were avoided in the past 
Table 3

\section{Results for Study Variables Baseline to Immediate Post-Intervention and Follow-Up Collapsed Across Study Groups}

\begin{tabular}{|c|c|c|c|c|c|c|c|}
\hline & \multicolumn{2}{|c|}{ Baseline } & \multicolumn{2}{|c|}{ Post } & \multicolumn{2}{|c|}{ Follow-Up } & \multirow[b]{2}{*}{$\begin{array}{c}\text { p value } \\
\mathrm{B} / \mathrm{P}, \mathrm{P} / \mathrm{F}, \mathrm{B} / \mathrm{F}\end{array}$} \\
\hline Variable & $\mathbf{N}$ & $\begin{array}{c}\text { Mean } \\
\text { (SD) }\end{array}$ & $\mathbf{N}$ & $\begin{array}{c}\text { Mean } \\
\text { (SD) }\end{array}$ & $\mathbf{N}$ & $\begin{array}{c}\text { Mean } \\
\text { (SD) }\end{array}$ & \\
\hline Knowledge $^{a}$ & 86 & $\begin{array}{c}7.64 \\
(7.18)\end{array}$ & 86 & $\begin{array}{l}16.44 \\
(6.09)\end{array}$ & 46 & $\begin{array}{c}8.80 \\
(9.18)\end{array}$ & $\leq .000, \leq .000, .295$ \\
\hline \multicolumn{8}{|l|}{ Intentions $^{\mathrm{b}}$} \\
\hline Alone & 84 & $\begin{array}{c}3.66 \\
(1.19)\end{array}$ & 84 & $\begin{array}{c}4.21 \\
(1.22)\end{array}$ & 46 & $\begin{array}{c}4.01 \\
(1.20)\end{array}$ & $.000, .875, .006$ \\
\hline Presence of peers & 85 & $\begin{array}{c}3.67 \\
(1.23)\end{array}$ & 84 & $\begin{array}{c}3.92 \\
(1.27)\end{array}$ & 46 & $\begin{array}{c}3.90 \\
(1.30)\end{array}$ & $.117, .442, .065$ \\
\hline \multicolumn{8}{|l|}{ Behavior } \\
\hline Spacer use* & 84 & $\begin{array}{l}2.23 \\
(.78)\end{array}$ & 81 & $\begin{array}{l}2.04 \\
(.84)\end{array}$ & 46 & $\begin{array}{l}1.93 \\
(.80)\end{array}$ & $.016, .209, .002$ \\
\hline Peak flow meter use* & 83 & $\begin{array}{l}2.51 \\
(.69)\end{array}$ & 81 & $\begin{array}{l}2.32 \\
(.76)\end{array}$ & 46 & $\begin{array}{l}1.98 \\
(.68)\end{array}$ & $.048, \leq .000, \leq .000$ \\
\hline $\begin{array}{l}\text { \# of days peak flow } \\
\text { meter used (past wk) }\end{array}$ & 85 & $\begin{array}{c}.60 \\
(1.44)\end{array}$ & 81 & $\begin{array}{c}1.19 \\
(2.00)\end{array}$ & 46 & $\begin{array}{c}2.24 \\
(2.50)\end{array}$ & $.003, .003, .000$ \\
\hline $\begin{array}{l}\text { \# of days spacer used } \\
\text { (past wk) }\end{array}$ & 83 & $\begin{array}{l}1.45 \\
(2.33)\end{array}$ & 80 & $\begin{array}{c}1.74 \\
(2.56)\end{array}$ & 46 & $\begin{array}{c}2.28 \\
(2.67)\end{array}$ & $.172, .267, .011$ \\
\hline $\begin{array}{l}\text { \# of times asthma triggers } \\
\text { avoided (past wk)* }\end{array}$ & 83 & $\begin{array}{c}2.30 \\
(1.35)\end{array}$ & 80 & $\begin{array}{c}2.33 \\
(1.43)\end{array}$ & 44 & $\begin{array}{c}2.11 \\
(1.37)\end{array}$ & $.945, .385, .419$ \\
\hline $\begin{array}{l}\text { \# of times bronchodilator was } \\
\text { used to stop asthma } \\
\text { (pastwk.)* }\end{array}$ & 84 & $\begin{array}{c}2.17 \\
(1.45)\end{array}$ & 77 & $\begin{array}{c}1.88 \\
(1.28)\end{array}$ & 46 & $\begin{array}{c}1.91 \\
(1.46)\end{array}$ & $.144, .750, .366$ \\
\hline $\begin{array}{l}\text { \# of times anti-inflammatory use } \\
\text { was skipped (past wk)* }\end{array}$ & 83 & $\begin{array}{c}2.13 \\
(1.36)\end{array}$ & 78 & $\begin{array}{c}2.05 \\
(1.34)\end{array}$ & 45 & $\begin{array}{c}2.00 \\
(1.36)\end{array}$ & $.784, .544, .851$ \\
\hline Self-Efficacy $^{c}$ & 86 & $\begin{array}{l}3.88 \\
(.69)\end{array}$ & 85 & $\begin{array}{l}4.07 \\
(.68) \\
\end{array}$ & 46 & $\begin{array}{l}3.89 \\
(.73) \\
\end{array}$ & $.008, .355, .254$ \\
\hline Self-Consciousness & 85 & $\begin{array}{c}2.28 \\
(1.53)\end{array}$ & 84 & $\begin{array}{c}2.23 \\
(1.56)\end{array}$ & 46 & $\begin{array}{c}2.16 \\
(1.53)\end{array}$ & $.726, .905, .941$ \\
\hline
\end{tabular}

${ }^{a}$ Results are presented as scores out of 42 .

${ }^{\mathrm{b}}$ Possible score range $=1-6$.

${ }^{\mathrm{c}}$ Possible score range $=1-5$.

*Non-parametric statistics were calculated for these variables because they were assessed using ordinal scales. Means/SD are shown for ease of interpretation.

$\mathrm{B}=$ Baseline, $\mathrm{P}=$ Post-Intervention, $\mathrm{F}=$ Follow-up.

week, number of times a bronchodilator was used to stop an asthma episode after it had started in the past week, and number of times an anti-inflammatory medication was skipped in the past week (see Table 3).

\section{Self-Efficacy}

There were statistically significant improvements in mean self-efficacy scores from baseline (mean $=3.88, \mathrm{SD}=.69)$ to immediate postintervention $($ mean $=4.07, \mathrm{SD}=.68), \mathrm{p}$ value $=$
.008 , but not from immediate post-intervention to 5 week follow-up, or from baseline to 5 week follow-up (see Table 3).

\section{Self-Consciousness}

After collapsing across groups, there were no statistically significant differences in mean selfconsciousness scores from baseline to immediate post-intervention, from immediate postintervention to 5 week follow-up, or from baseline to 5 week follow-up (see Table 3). 


\section{Discussion}

The purpose of this study was to evaluate the effects of an asthma education intervention on knowledge, self-efficacy, and self-consciousness among adolescent asthmatics. Additional variables were also assessed, including selfreported asthma management behaviors (utilization of peak flow meters, holding chambers, and inhalers, trigger avoidance, and medication adherence) and intentions related to those behaviors when alone and when in the presence of peers. While there were no statistically significant differences at post-test between the two study groups for any of the variables studied, after controlling for baseline values, there were statistically significant improvements from baseline to follow-up, indicating that there were changes over time, after both groups had received the intervention.

Specifically, improvements were noted in knowledge and self-efficacy from baseline to immediate post-intervention. Improvements were noted for intention (when alone) from baseline to post-intervention and from baseline to five week follow-up. Improvements in holding chamber use were noted from baseline to post-intervention and from baseline to five week follow-up. Improvements were also noted for the number of days a holding chamber was used in the past week from baseline to five week follow-up. For both of these instances, the holding chamber was used in conjunction to daily medication use rather than as a result of experiencing more asthma symptoms. Furthermore, improvements were noted for all time periods (baseline to post-intervention, postintervention to five week follow-up, and baseline to five week follow-up) for current peak flow meter use and for the number of days a peak flow meter was used in the past week.

This intervention did not appear to have an effect on the self-consciousness variable; the asthmatic adolescents in this study did not report feelings of self-consciousness about their asthmatic condition. Asthma prevalence is high among this population; therefore, it is possible that the asthmatic adolescents studied are not self-conscious about their condition because so many of their peers also have asthma. This is in contrast to the findings of one focus group. According to the authors of that study, although the majority of participants stated that they were not afraid to tell others about their condition, or to take their medications in front of others, a few were afraid that the reaction from others would be negative (Van Es et.al., 1998). More research is needed to determine the true impact of this variable on asthma-related behaviors, but it did not appear to be influenced by the intervention in this study.

The primary limitation associated with this study was low statistical power. Compared to other authors whom reported statistically significant improvements in knowledge and self-efficacy between intervention and comparison groups, we did not find such differences between groups (Evans et al., 1987; Shaw et al., 2005; \& Bursch et al., 1999). It is possible that the intervention did have a positive impact on these variables (there were non-significant improvements for some of the variables, including the self-efficacy variable), but the sample size may have been too small to detect such changes. An attempt was made, however, to increase power by collapsing across groups to make within group comparisons over time.

Selection bias was another limitation associated with this study. Non-randomization of participants to intervention and comparison groups posed a threat to internal validity and the conclusions drawn about the effectiveness of the intervention. Although baseline values of variables were statistically controlled for, and there were no differences for any of the demographic variables between groups, selection bias cannot be ruled out. Additionally, participants in this study were selected based on asthma medication use in their medical records. Since there is a wide variance in asthma classification (mild intermittent, mild persistent, moderate persistent, and severe persistent), it is possible that those with more severe asthma had greater knowledge of asthma medications and/or device use before the start of the intervention compared to those with less severe asthma. 
Since we did not statistically control for this variable, this must also be considered as a possible limitation associated with this study.

There were several additional limitations associated with this study. Although the original quasi-experimental study design allowed us to determine if there were short-term differences in the study variables, no differences were found at post-test. However, when the results from the delayed intervention group (comparison) were combined with those of the intervention group, differences were seen for some of the variables from pre-test to post-test. While these results are promising, the test-retest format does not allow us to draw conclusions regarding the causal effect of the intervention, or whether the improvements seen will be maintained over time. Also due to the collapsing of the groups, the comparison group completed an additional assessment relative to the intervention group making the groups non-equivalent in this regard, which might have also influenced the results of this study. In addition, the asthma knowledge questionnaire developed by Fitzclarence and Henry was created in 1992, which was over ten years ago. Therefore, some of the items in this questionnaire may not adequately reflect current asthma knowledge since the field has evolved over time. Furthermore, possible respondent effects may have occurred, specifically "helpful subject effects." It is possible that participants became aware of the aim of the study and answered questions in a favorable manner, especially after the participants received the intervention. Lastly, experimenter bias may have posed a threat since the first author collected the data and delivered all of the intervention components.

The primary strength of this study was the use of a comparison group during the first three weeks of the intervention from baseline to postintervention. This ruled out potential biases including maturation, testing, and instrumentation. It also allowed for statistical control of possible baseline differences in key variables. Differences at post-intervention, however, were difficult to detect given the small sample size.

Additionally, the Kickin' Asthma curriculum used in this study was designed specifically for asthmatic adolescents. This study also incorporated key SCT constructs, including selfefficacy, observational learning, reinforcement, and social outcome expectations, to help strengthen the intervention and examine important outcomes related to asthma-related behavior.

This research confirms the potential benefits associated with this asthma education intervention. Although there were no statistically significant differences found between groups at post-intervention, statistically significant improvements were noted after collapsing across groups for a number of the variables. The most consistent improvements from baseline to immediate post-intervention and from immediate post-intervention to the five followup were found for the behavior change variables.

While this study provided a foundation, additional studies, broader in scope and power, are needed in order to truly understand the impact of this intervention on a population of asthmatic adolescents. Future research using the variables described in this study, along with an examination of additional variables, such as emergency room visits and school absenteeism rates, is needed to determine the potential impact of such an intervention

\section{References}

American Lung Association. Asthma Programs, 2010. Available at: http://www.lungusa.org. Accessed October 14, 2010.

Asthma and Allergy Foundation of America. Asthma overview, 2005. Available at: http://www.aafa.org. Accessed July 2, 2010.

Berg, J., Tichacek, M.J., \& Theodorakis, R. (2004). Evaluation of an educational program for adolescents with asthma. The Journal of School Nursing, 20,29-35. 
Bruzzese, J.M., Bonner, S., Vincent, E.J., Sheares, B.J., Mellins, R.B., \& Levison, M.J. (2004). Asthma education: The adolescent experience. Patient Education and Counseling, 55, 396-406.

Bursch, B., Schwankovsky, L., Gilbert, J., \& Zeiger, R. (1999). Constriction and validation of four childhood asthma self-management scales: Parent barriers, child and parent self-efficacy, and parent belief in treatment efficacy. Journal of Asthma, 36, 115-128.

Buston, K.M., \& Wood, S. F. (2000). Non compliance amongst adolescents with asthma: Listening to what they tell us about self-management. Family Practice,17, 134-138.

California Health Interview Survey. Californians miss 3.9 million days of work or school a year due to asthma, 2005. Available at: http://www.chis.ucla.edu. Accessed July 20, 2010.

Centers for Disease Control and Prevention. National Center for Health Statistics. National Health Interview Survey Raw Data, 2008. Available at: http://www.cdc.gov. Accessed July 2, 2010.

Christiansen, S.C. \& Zuraw, B.L. (2002). Serving the underserved: School-based asthma intervention programs. Journal of Asthma, 39, 463-472.

Environmental Protection Agency. (2001). Indoor Air Quality (IAQ). Indoor Air Quality in Schools. Available at: http://www.epa.gov. Accessed October 1, 2010.

Evans, D., Clark, N.M., Feldman, C.H., Rips, J., Kaplan, D., Levison, M.J., et al. (1987). A school health education program for children with asthma aged 8-11 years. Health Education Quarterly, 14, 267-279.

Fitzclarence, C.A.B., \& Henry, R.L. (1990). Validation of an asthma knowledge questionnaire. Journal of Pediatric and Child Health, 26, 200-204.

Gibson, P.G., Henry, R.L., Vimpani, G.V., \& Halliday, J. (1995). Asthma knowledge, attitudes, and quality of life in adolescents. Archives in Diseases in Childhood, 73, 321-326.

Gibson, P.G., Shah, S., \& Mamoon, H.A. (1998). Peer-led asthma education for adolescents: Impact evaluation. Journal of Adolescent Health, 22, 66-72.

Lurie, N. (1998). Incorporating asthma education into a traditional school curriculum. American Journal of Public Health, 88, 822-823.

Magzamen, S., Patel, B., Davis, A., Edelstein, J., \& Tager, I.B. (2008). Kickin’ Asthma: School-based asthma education in an urban community. Journal of School Health, 78, 655-665.

MayoClinic. (1998-2010). Asthma. Treatments and drugs. Available at http://www.mayclinic.com. Accessed October 1, 2010.

Mesters, I., Meertens, R., Crebolder, H., \& Parcel, G. (1993). Development of a health education program for parents of preschool children with asthma. Health Education Research, Theory, and Practice, 8, 53-68.

McGhan, S.L., Wong, E., Jhangri, G.S., Wells, H.M., Michaelchuk, D.R., Boechler, V.L., et al. (2003). Evaluation of an education program for elementary school children with asthma. Journal of Asthma, 40, 523-533.

National Heart, Lung, and Blood Institute. (2007). National Asthma Education and Prevention Program. Expert Panel Report 3: Guidelines for the Diagnosis and Management of Asthma. Available at http://www.nhlbi.nih.gov. Accessed October 1, 2010.

Price, J. (1996). Issues in adolescent asthma: What are the needs? Thorax, 51, S13- S17.

Price, J. \& Kemp, J. (1999). The problems of treating adolescent asthma: What are the alternatives to inhaled therapy? Respiratory Medicine, 93, 677-684.

Shaw, S.F., Marshak, H.H., Dyjack, D.T., \& Neish, C.M. (2005). Effects of a classroom-based asthma education curriculum on asthma knowledge, attitudes, self-efficacy, quality of life, and selfmanagement behaviors among adolescents. American Journal of Health Education, 36, 140-145.

Thies, K.M. \& McAllister, J.W. (2001). The health and education leadership project: A school initiative for children and adolescents with chronic health conditions. Journal of School Health, 71, 167172.

Valeros, L., Kieckhefer, G., \& Patterson, D. (2001). Traditional asthma education for adolescents. Journal of School Health, 71, 117-119. 
Van Es, S.M., le Coq, E.M., Brouwer, A.I., Mesters, I., Nagelkerke, A.F., Colland, V.T. (1998).

Adherence-related behavior in adolescents with asthma: Results from focus group interviews. Journal of Asthma, 35, 637-646.

Author Information

Kara Zografos, DrPH, MPH*

Department of Public Health

California State University, Fresno

2345 E. San Ramon Avenue

M/S MH 30

Fresno, CA 93740

Telephone: 559-278-5988;

Fax: 559-278-4179;

Email: kzografos@csufresno.edu

Helen Hopp Marshak, PhD, MS, CHES

Department of Health Promotion and Education

Loma Linda University

David T. Dyjack, PhD

Department of Environmental and Occupational Health Loma Linda University

Christine Neish, $\mathrm{PhD}$

Department of Health Promotion and Education

Loma Linda University

* corresponding author 